\title{
Pregabalin treatment for neuropathic pain may damage intervertebral disc tissue
}

\author{
NUMAN KARAARSLAN ${ }^{1}$, IBRAHIM YILMAZ ${ }^{2}$, DUYGU YASAR SIRİN ${ }^{3}$, HANEFI OZBEK ${ }^{2}$, NECATI KAPLAN ${ }^{4}$, \\ YASIN EMRE KAYA ${ }^{5}$, YENER AKYUVA ${ }^{6}$, MEHMET SABRI GURBUZ $^{7}$, KADIR OZNAM $^{8}$ and OZKAN ATES $^{9}$ \\ ${ }^{1}$ Department of Neurosurgery, Namik Kemal University School of Medicine, Tekirdag 59100; \\ ${ }^{2}$ Department of Medical Pharmacology, Istanbul Medipol University School of Medicine, Istanbul 34810; \\ ${ }^{3}$ Department of Molecular Biology and Genetics, Faculty of Arts and Sciences, Namik Kemal University, \\ Tekirdag 59030; ${ }^{4}$ Department of Neurosurgery, Istanbul Rumeli University, Corlu Reyap Hospital, \\ Tekirdag 59860; ${ }^{5}$ Department of Orthopedic and Traumatology, Abant Izzet Basal University School of Medicine, \\ Bolu 14000; ${ }^{6}$ Department of Neurosurgery, Gaziosmanpasa Taksim Training and Research Hospital, \\ Istanbul 34433; ${ }^{7}$ Department of Neurosurgery, Istanbul Medeniyet University School of Medicine, Istanbul 34730; \\ ${ }^{8}$ Department of Orthopedic and Traumatology, Istanbul Medipol University School of Medicine, Istanbul 34214; \\ ${ }^{9}$ Department of Neurosurgery, Istanbul Esenyurt University, Esencan Hospital, Istanbul 34517, Turkey
}

Received November 9, 2017; Accepted March 23, 2018

DOI: $10.3892 /$ etm.2018.6289

\begin{abstract}
The aim of the present study was to determine whether pharmaceutical preparations with pregabalin (PGB) as an active ingredient, which are widely prescribed by clinicians, exert toxic effects on human primary nucleus pulposus (NP) and annulus fibrosis (AF). Primary human cell cultures were obtained from intact $(n=6)$ and degenerated $(n=6)$ tissues resected from the two groups of patients. Different doses of PGB were applied to these cultures and cells were subjected to molecular analyses at 0,24 and $48 \mathrm{~h}$. Cell vitality, toxicity and proliferation were assessed using a spectrophotometer. The expression of chondroadherin (CHAD), a (member of the NP-specific protein family), hypoxia-inducible factor- $1 \alpha$ (HIF-1 $\alpha$ ) and type II collagen (COL2A1) was measured using reverse transcription-quantitative polymerase chain reaction. The results revealed that cell intensity increased in a time-dependent manner and cell vitality continued in the cultures without pharmaceuticals. Cell proliferation was suppressed in the PGB-treated cultures independent from the dose and duration of application. PGB was demonstrated to suppress the expression of CHAD and HIF-1 $\alpha$. In contrast, COL2A1 gene expression was not revealed in any experimental group. The present study utilized an in vitro model and
\end{abstract}

Correspondence to: Dr Numan Karaarslan, Department of Neurosurgery, Namik Kemal University School of Medicine, 1-14 Campus Street, Tekirdag 59100, Turkey

E-mail: numikara@yahoo.com

Key words: annulus fibrosis, chondroadherin, type II collagen, hypoxia-inducible factor- $1 \alpha$, intervertebral disc, nucleus pulposus, pregabalin, primary cell culture, cytotoxicity the PGB active ingredient used herein may not be representative of clinical applications; however, the results demonstrated that PGB has a toxic effect on NP/AF cell cultures containing primary human intervertebral disc tissue. In summary, the use of pharmacological agents containing PGB may suppress the proliferation and differentiation of NP/AF cells and/or tissues, which should be considered when deciding on an appropriate treatment regime.

\section{Introduction}

Pregabalin (PGB) is a GABA analogue structured pharmacological agent (1). PGB is a calcium canal ligand of $\alpha 2-\delta$ and acutely connects to the $\alpha 2-\delta$ subunit protein of voltage-gated calcium channels, inducing calcium release in nerve endings to inhibit the release of neurotransmitters, including glutamate, noradrenaline and substance P (2). Owing to its chemical structure and pharmaceutical features, PBG is used as a treatment for epilepsy, peripheral neuropathic pain (3), chronic musculoskeletal pain, postoperative pain following lumbar-surgery (4), anxiety, somnipathy and fibromyalgia (5). PGB is also frequently prescribed in neurology, neurosurgery, orthopedics, traumatology, rheumatology, physical medicine and rehabilitation, geriatrics, anesthesia, immunology, dermatology and endocrinology clinics (3-5). PBG has been reported to have a number of adverse side effects, including vertigo, somnolence, brain fog, ataxia, tremor and dysarthria $(6,7)$. However, to the best of our knowledge, it has not been conclusively determined whether PGB has any adverse effects on intervertebral disc tissues.

A modern focus of neurosurgery is the total repair of damaged tissues, both mechanically and biologically, with the help of regenerative and reparative medicine $(8,9)$. Pharmacological treatments are able to accumulate in tissues, including the synovial liquid compartments, irrespective 
of the route of administration, may (10-12). In the present study, PGB was applied to human nucleus pulposus (NP) and annulus fibrosis (AF) cell cultures. Fibroblast cells proliferate and are replaced by tissue that undergoes degeneration during the healing process, particularly in trauma affecting the NP/AF cells $(8,9)$. In order to prevent undesired fibroblast proliferation, the implantation of cultured NP/AF cells during therapy was discussed in recent studies $(8,9)$. Exposure to pharmacological agents may affect the healthy proliferation of desired NP/AF cells and negatively affect the formation of micro-environmental structures, including the extracellular matrix (ECM) (13). The aim of the present study was to conduct a pharmaco-molecular analysis of the effects of PGB on type II collagen (COL2A1), the protein responsible for ECM development, as well as on chondroadherin (CHAD) $(13,14)$ and hypoxia-inducible factor-1 $\alpha$ (HIF-1 $\alpha)(15,16)$, which are NP specific marker proteins responsible for spinal cord and dorsal column development.

The intervertebral disc (IVD) is composed of a central gelatinous NP surrounded by elastic, ligamentous AF and is flanked superiorly and inferiorly by cartilaginous endplates $(8,9)$. NP cells are specialized and share some characteristics with articular chondrocytes in terms of aggrecan, COL2A1 and Sry-box 9 protein expression (17). However, compared with articular cartilage (AC), the NP retains a unique ECM with a higher glycosaminoglycan to hydroxyproline ratio and its native cells have distinctive gene expression signatures (18). The initial stages of IVD are associated with reduced cellularity, aberrant cell function, loss of proteoglycans and concomitant tissue dehydration $(8,9)$. As cells within the IVD are liable for ECM maintenance and homeostasis, they serve important roles in the degenerative process $(8,9)$. Previous studies have demonstrated that mature NP cells are generated from precursor notochordal cells (NCs), although NP cells are morphologically different to NCs and express different genes $(19,20)$.

However, it is evident that the NP contains multiple cell subpopulations $(8,9)$. This cellular heterogeneity may represent different stages of proliferation, differentiation and maturation; however, relatively little information is available regarding these NP cell subpopulations. Successful development of cell replacement treatments and IVD regeneration is dependent on an in-depth understanding of the cellular and molecular characteristics of functional IVD (17). CHAD is a protein predominantly expressed in the ECM of the cartilaginous tissue and the IVD $(8,9,13,14,21)$. CHAD interacts with the collagen fibrils of the ECM and the cell surface molecules; further, CHAD regulates the cell metabolism and ECM structure $(8,9)$. Changes in CHAD expression may therefore lead to pathological changes to the tissues over time $(13,14,21)$.

HIF-1 $\alpha$ regulates the key molecules associated with NP cell survival, apoptosis, autophagy and matrix synthesis (22). In addition, the HIF status and activity designates the response of the NP cells under hypoxic and normoxic conditions (23).

\section{Materials and methods}

Ethical approval. The present study was approved we obtained permission from the ethics committee of the Namik Kemal University School of Medicine (Tekirdag, Turkey). Written informed consent was obtained from all study subjects. Researchers were blinded to dosages and agents used. Analyses were performed by the same researchers and were repeated at least thrice to minimize the experimental errors.

Selection criteria. Tissues were obtained from the patients with back and/or leg pain admitted to the Department of Neurosurgery, Namik Kemal University, School of Medicine between February 2017 and June 2017. Following physical and neurological examinations, magnetic resonance imaging (MRI) was performed and patients with lumbar disc hernia were identified and included in the present study. A total of 15 patients were recruited, however patients with malignancy $(n=1)$, using biological agents $(n=1)$, with a history of smoking or alcohol consumption $(\mathrm{n}=2)$, taking beta-blocker drugs $(n=2)$, erythromycin $(n=1)$ or fluoxetine $(n=2)$ were excluded from the study (10-12). Degenerated disc hernia (extruded or migrated disc fragments) compressing the nerve roots and/or the spinal cord were harvested, and the amount of disc degeneration was graded according to Pfirrmann classification using T2 weighted MRI (24). Lumbar microdiscectomy was performed under endotracheal general anesthesia to the patients placed in prone position through median skin incision. Degenerated intervertebral disc tissue was resected during the surgery. Tissues obtained from 6 patients, included 3 females and 3 males (mean body mass index, $28.7 \mathrm{~kg} / \mathrm{m}^{2}$; mean age, $39.98 \pm 11.16$ years) were resected and transferred into sterile falcon tubes containing penicillin streptomycin. The control group comprised of volunteers admitted to the Emergency Department of Republic of Turkey, Ministry of Health, State Hospital (Tekirdag, Turkey). A total of 6 patients with vertebral fractures in the thoracolumbar/lumbar region and additional spinal cord compression were diagnosed with instability and traumatic intervertebral disc hernia following lumbar MRI. They underwent laminectomy and discectomy. These cases were similar in terms of sex ( 3 male and 3 female), age and body mass index (mean age, $40.62 \pm 13.46$ years; mean body mass index: $\left.27.2 \mathrm{~kg} / \mathrm{m}^{2}\right)$.

Tissue explant and preparation of primary cell cultures. Discs and granulation tissues were transferred to the laboratory Dulbecco's modified Eagle's medium (DMEM; Gibco; Thermo Fisher Scientific, Inc., Waltham, MA, USA) supplemented with $1 \%$ penicillin-streptomycin, $15 \%$ fetal bovine serum (FBS) and 1\% L-glutamine (all Gibco; Thermo Fisher Scientific, Inc., Waltham, MA, USA). Tissue samples were irrigated with $0.9 \%$ isotonic sodium chloride solution in the laminar flow cabinet and clarified from the red blood cells. Tissues were dissected into $0.4 \mathrm{~cm}^{3}$ pieces, washed in Hank's balanced salt solution (Gibco; Thermo Fisher Scientific, Inc.) and transferred to Falcon tubes. Subsequently, $0.375 \mathrm{mg}$ collagenase type II enzyme (Gibco; Thermo Fisher Scientific, Inc.) dissolved in DMEM were added and incubated with $5 \% \mathrm{CO}_{2}$ at $37^{\circ} \mathrm{C}$ overnight. The samples were subsequently centrifuged at $4^{\circ} \mathrm{C}$ and $161 \mathrm{x} \mathrm{g}$ for $10 \mathrm{~min}$. Cell pellets were resuspended by adding the cell culture medium, transferred to T75 flasks and incubated at $37^{\circ} \mathrm{C}$ for $72 \mathrm{~h}$ to obtain the primary cell cultures. Following incubation, cells were trypsinized with trypsin-EDTA $(0.25 \%)$. Once they reached confluence, cells in the primary culture were passaged stained with Trypan 
blue at $37^{\circ} \mathrm{C}$ for $12 \mathrm{~min}$ and counted. Counting was performed manually under normal laboratory conditions at $22.4^{\circ} \mathrm{C}$ using a light microscope (magnification, x40). Cells were seeded in 96-well plates at a density of $1.4 \times 10^{4}$ cells/well for MTT analysis, in 24 well plates at a density of $3.4 \times 10^{4}$ cells/well for acridin orange/propidium iodide (AO/PI) analysis and in $100 \mathrm{~mm}$ petri dishes at a density of $4.4 \times 10^{6}$ cells/dish for RNA isolation.

Drug preparation. The main stock solutions of PGB (Lyrica capsule $^{\circledR}$; Pfizer, Inc., New York, NY, USA) were prepared freshly as $150 \mathrm{mg} / \mathrm{ml}$ by dissolving in DMEM. Thereafter, the main stock solutions were transferred to sterilized thick bottles, which had different pharmaceutical colors and thus color-coding was performed. Preliminary experiments were performed to investigate the optimum dose of PGB; concentrations of 1,50, 100 and 1,000 $\mu \mathrm{M}$ PGB were applied to human primary NP/AF cell cultures. It was observed that $>100 \mu \mathrm{M}$ PGB completely inhibited cell proliferation (data not shown), so a final concentration of $100 \mu \mathrm{M}$ was selected. Tissues were divided into the following groups: 1, untreated intact (i) AF/NP group; 2, untreated degenerated (d)AF/NP group; 3, iAF/NP treated with PGB; and 4, dAF/NP treated with $100 \mu \mathrm{M}$ PGB. Images were obtained from cell cultures using inverted light and/or fluorescent microscope at x4, x10, x20 and x40. Cell viability was analyzed using a commercial MTT kit (Vybrant MTT Cell Proliferation Assay; Thermo Fisher Scientific, Inc.) according to the manufacturer's protocol. MTT analyses were performed prior to and following drug administration and were recorded using an ELISA microplate reader at $540 \mathrm{~nm}$.

Morphological evaluation by inverted and fluorescence microscopy. Images of cell organizations of AF/NP cultures were recorded confocally at a magnification of x10 under a phase-contrast microscope. Morphological evaluations were performed under normal conditions at $22.4^{\circ} \mathrm{C}$ for $10 \mathrm{~min}$. The AO/PI stain was prepared with $10 \mathrm{~g}$ sodium-EDTA, $4 \mathrm{mg}$ PI, $50 \mathrm{ml} \mathrm{FBS}$ and $4 \mathrm{mg}$ AO dissolved in $2 \mathrm{ml} \mathrm{99 \%}$ ethanol, and was mixed into wells; sterile distillated water was added to reach a final volume of $200 \mathrm{ml}$. Cell cultures were stained with $\mathrm{AO} / \mathrm{PI}$ at room temperature for $10 \mathrm{~min}$, and then cell death and cell viable were monitored at a magnification of $\mathrm{x} 10$ using a fluorescent microscope. Microphotographs of cell structures were obtained and the images were evaluated using CytoVision ${ }^{\circledR}$ (version 7.0; Genetix; Leica Microsystems, Inc., Buffalo Grove, IL, USA) capture station imaging program.

MTT analyses. The cell viability tests were performed using a commercial MTT kit (Vybrant MTT Cell Proliferation Assay; Thermo Fisher Scientific, Inc.), which inhibits formazan crystal formation in dead cells. Analyses were performed prior to and following PGB addition. The cell culture medium was removed and replaced with a fresh MTT solution [MTT dissolved in $1 \mathrm{ml}$ sterile PBS at a $\mathrm{pH}$ of 7.4 to prepare stock solution $(12 \mathrm{mM})]$. The stock solution was diluted with DMEM (10\%) and $100 \mu \mathrm{l}$ of this solution added to each well. Following a $150 \mathrm{~min}$ incubation period at $37^{\circ} \mathrm{C}$ in a dark, DMSO was then added and the samples were incubated for $10 \mathrm{~min}$ at $37^{\circ} \mathrm{C}$. The absorbance was recorded at $540 \mathrm{~nm}$. The viability of the control group prior to contrast agent addition was accepted as $100 \%$.

Gene expression analysis by reverse transcription-quantitative polymerase chain reaction $(R T-q P C R)$. Total RNA was extracted from cultured iAF/NP and $\mathrm{dAF} / \mathrm{NP}$ cells using a PureLink RNA Mini kit (cat. no. 12183018A; Ambion; Thermo Fisher Scientific, Inc.) and 2-mercaptoethanol (Thermo Fisher Scientific, Inc.). Purified RNA (50 ng) was reverse-transcribed to complementary (c)DNA using a High Capacity cDNA Reverse Transcription kit (cat. no. 4368814; Thermo Fisher Scientific, Inc.) according to the manufacturer's protocol.qPCR analyses were performed on the cDNA to analyze the changes in gene expression using TaqMan Gene Expression Assays kits for CHAD (cat. no. 4448892; assay ID Hs00154382_m1), HIF-1 $\alpha$ (cat.no. 4453320; assay ID Hs00153153_m1), COL2A1 (cat. no. 4453320; assay ID Hs00264051_m1), and the internal control (housekeeping) gene $\beta$-actin (cat. no. 4453320; assay ID Hs99999903_m1; Thermo Fisher Scientific, Inc.). Each gene was amplified using an RT-qPCR reaction mix prepared with $1 \mu \mathrm{l}$ TaqMan Gene Expression Assay, $10 \mathrm{ml}$ of TaqMan Gene Expression Master Mix, $4 \mathrm{ml}$ of cDNA template and UltraPure DNase/RNase-Free distilled water on MicroAmp Fast Optical 96-well reaction plates.

The Applied Biosystems 7300/7500 RT-PCR system was used with the following reaction protocol: Hold at $50^{\circ} \mathrm{C}$ for $2 \mathrm{~min}$, hold at $95^{\circ} \mathrm{C}$ for 10 and $1 \mathrm{~min}$ at $60^{\circ} \mathrm{C}$ for 40 cycles. The gene expression levels were normalized by the expression of $\beta$-actin for each sample and fold changes were evaluated using the $2^{-\Delta \Delta C q}$ method $(8,9,25)$.

Cultures formed from intact AFCs/NPCs formed the control group, named as Group 1. The gene expression levels in this group (non-PGB group), were normalized by $\beta$-actin gene expression, used as endogenous control and target gene expressions were accepted as $100 \%$ [Relative quantitation $(R Q)=1$ ] The RQ values in other groups were also normalized by $\beta$-actin gene expression and increase/decrease of target genes COL2A1, HIF- $1 \alpha$ and CHAD expressions in the experimental groups was compared with that in Group 1 to obtain the RQ values.

Statistical analysis. Minitab software (version 16; Minitab Ltd., Coventry, United Kingdom) was used to analyze the result of the present study. All data are presented as the mean \pm standard deviation and were evaluated using one-way analysis of variance with a post hoc Tukey test. $\mathrm{P}<0.05$ was considered to indicate a statistically significant difference.

\section{Results}

Morphological analysis of NP/AF cell cultures. Confluent cells in primary cultures obtained from both intact and degenerated tissues were treated with trypsin to obtain cell suspensions. Following $24 \mathrm{~h}$ of incubation, the experiment was initiated and treatments were administered. The cell confluence at $0 \mathrm{~h}$ was higher in iAFC/NPC cultures compared with the dAFC/NPC cultures (Fig. 1A). In the microphotographs in Fig. 1B, the cells in the dAFC/NPC culture samples had fewer and less viable cells compared with the cells in the iAFC/NPC culture samples. However, in these images, it was evident that the viability and proliferation of PGB-treated cells were suppressed. In 
A
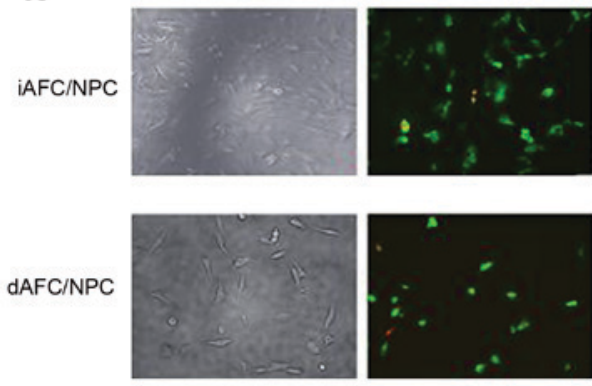

B

PGB (-)

$\mathrm{PGB}(+)$
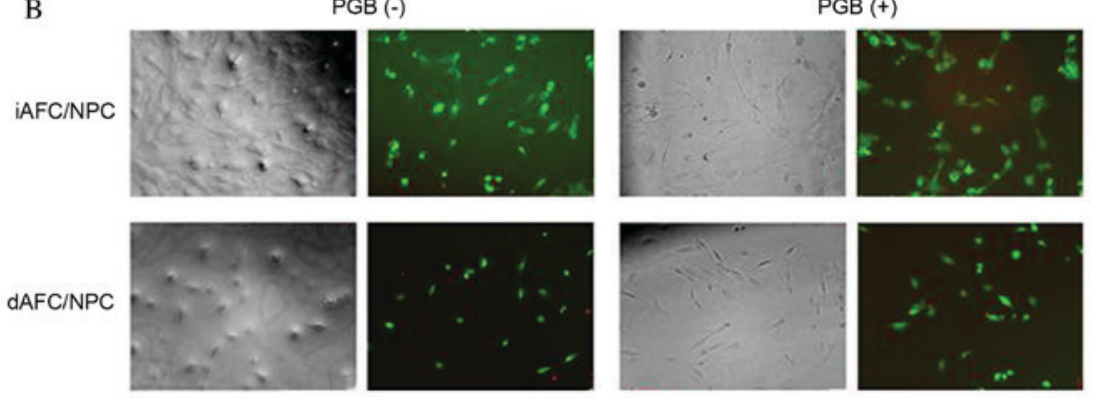

$\mathrm{C}$

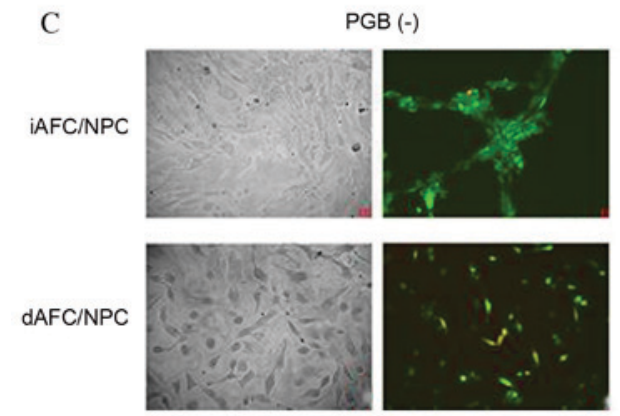

PGB (-)

$\mathrm{PGB}(+)$
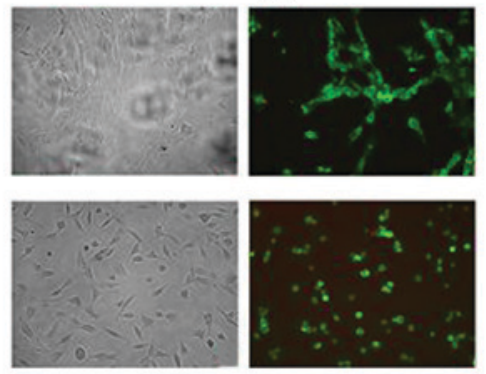

Figure 1. Inverted microscopy and acridin orange/propidium iodide staining of iAFC/NPC and dAFC/NPC treated with or without pregabalin for (A) 0 , (B) 24 and (C) $48 \mathrm{~h}$. iAFC/NPC, intact annulus fibrosis/nucleus pulposus tissue; dAFC/NPC, degenerated annulus fibrosis/nucleus pulposus tissue; PGB, pregabalin.

Fig. 1C, in addition to the suppression of the proliferation in the PGB-administered group, the integrity of the matrix of the extracellular construct was occasionally impaired compared with the control group. In summary, in all the samples in the control group, the cells were alive, healthy and proliferative compared with the PGB-administered samples. Additionally, the ECM structure in microphotographs of all of the samples in all control groups maintained its integrity.

Cell viability, toxicity and proliferation. Cell viability and proliferation were evaluated using AO/PI staining and MTT analysis in all the experimental groups. The results revealed that, in $\mathrm{dAFC} / \mathrm{NPC}$ tissues, cell proliferation was significantly increased in the untreated group compared with the PGB-treated group $(\mathrm{P}<0.05$; Table I).

Evaluation of $R T-q P C R$ analysis. The results of RT-qPCR revealed that COL2A1 was not expressed in AFC/NPC cultures in the experimental groups (Fig. 2). In untreated iAFC/NPC tissues, HIF-1 $\alpha$ and CHAD expression was markedly decreased at 24 and $48 \mathrm{~h}$ compared with $0 \mathrm{~h}$. It was observed that, compared with untreated iAFC/NPC tissues at $0 \mathrm{~h}, \mathrm{CHAD}$ and HIF-1 $\alpha$ expression was decreased in
$\mathrm{dAFC} / \mathrm{NPC}$ tissues at 0 and $24 \mathrm{~h}$. However, CHAD expression was significantly upregulated at $48 \mathrm{~h}$ in the dAFC/NPC group compared with the untreated $\mathrm{iAFC} / \mathrm{NPC}$ group at $0 \mathrm{~h}$; HIF-1 $\alpha$ expression remained markedly decreased. In iAFC/NPC tissues, no significant difference in CHAD expression was observed between treated and untreated cells at 24 and $48 \mathrm{~h}$, however this change was significant when compared with the untreated iAFC/NPC group at $0 \mathrm{~h}$. HIF-1 $\alpha$ expression was markedly decreased in PGB-treated iAFC/NPC tissues compared with untreated iAFC/NPC tissues at $24 \mathrm{~h}$ and the expression was significantly decreased in PGB-treated iAFC/NPC tissues at 24 and $48 \mathrm{~h}$ compared with the untreated iAFC/NPC group at $0 \mathrm{~h}$. In PGB-treated dAFC/NPC tissues, HIF-1 $\alpha$ expression at 24 and 48 h was significantly decreased, and CHAD is significantly increased at $24 \mathrm{~h}$ and decreased at $48 \mathrm{~h}$ compared with the the untreated iAFC/NPC group at $0 \mathrm{~h}$.

\section{Discussion}

PGB is a GABA analogue that blocks neurotransmitter release via calcium channels mediated in the presynaptic ends although it does not affect through GABA receptors (26). It has previously been reported that PGB has no analgesic effect (27). 
Table I. Assessment of the cell viability of intact and degenerate tissues following pregabalin treatment.

Proliferation (optical density)

\begin{tabular}{llll}
\cline { 2 - 4 } Application & \multicolumn{1}{c}{$0 \mathrm{~h}$} & \multicolumn{1}{c}{$24 \mathrm{~h}$} & $48 \mathrm{~h}$ \\
\hline Control degenerate tissue & $0.270 \pm 0.01$ & $0.230 \pm 0.01$ & $0.197 \pm 0.00$ \\
Degenerate tissue & $0.198 \pm 0.01^{\mathrm{a}}$ & $0.234 \pm 0.01^{\mathrm{a}}$ & $0.189 \pm 0.01^{\mathrm{a}}$ \\
Control intact tissue & $0.270 \pm 0.01$ & $0.232 \pm 0.01$ & $0.360 \pm 0.00$ \\
Intact tissue & $0.230 \pm 0.01^{\mathrm{b}}$ & $0.246 \pm 0.01^{\mathrm{b}}$ & $0.244 \pm 0.02^{\mathrm{b}}$
\end{tabular}

${ }^{\mathrm{a}} \mathrm{P}<0.05$ vs. control degenerate tissue and ${ }^{\mathrm{b}} \mathrm{P}<0.05$ vs. control intact tissue. Data was analysied using a one-way analysis of variance followed by a post-hoc Turkey Pairwise Comparison test.

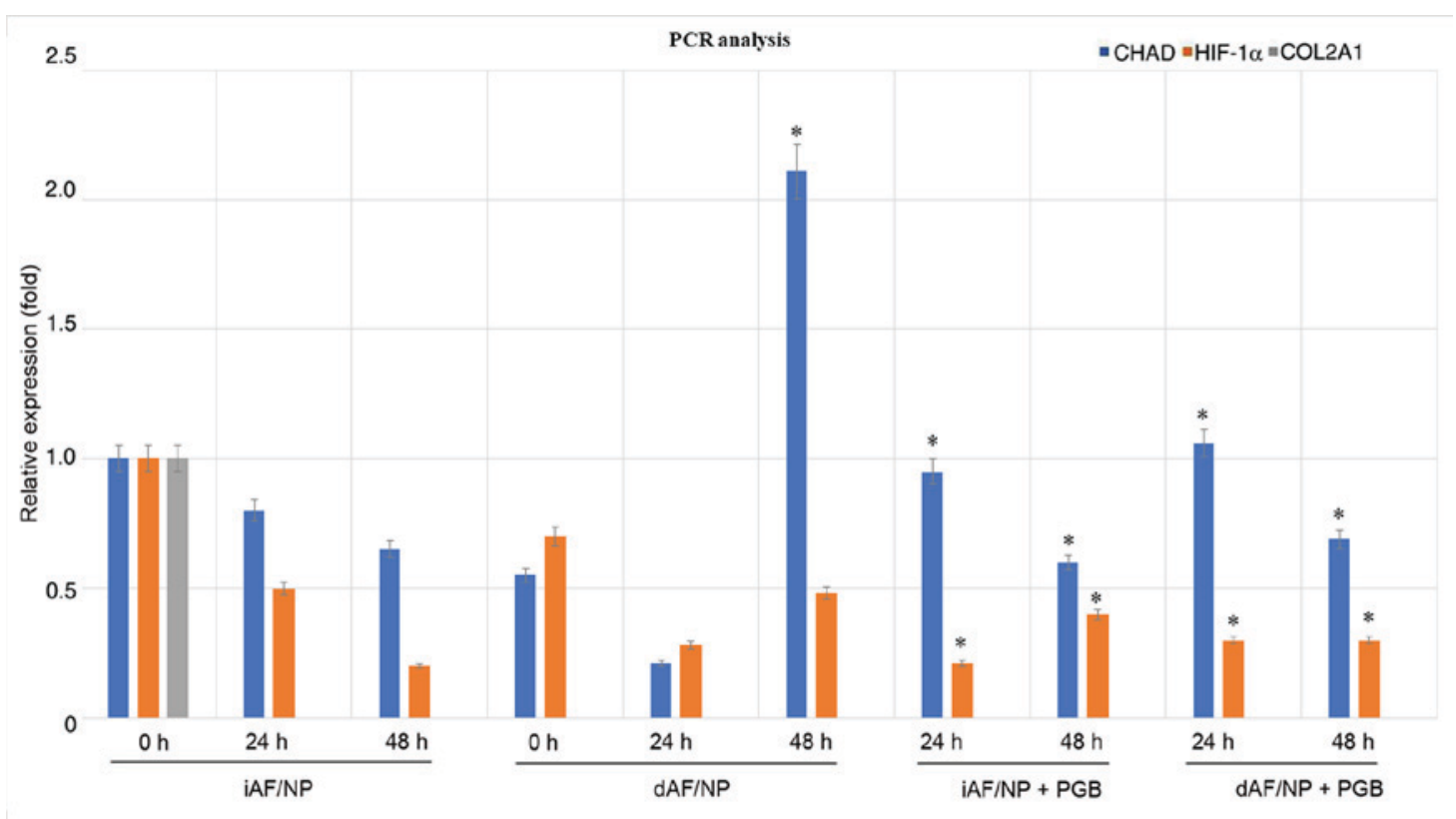

Figure 2. Cultures were prepared from iAFC/NPC $(n=6)$ and $\mathrm{dAFC} / \mathrm{NPC}(\mathrm{n}=6)$ tissues resected from the two groups of patients and treated with or without PGB. The expression of HIF-1 $\alpha$, CHAD and COL2A1 was assessed at 0,24 and $48 \mathrm{~h}$. "P<0.05 vs. $0 \mathrm{~h}$. iAFC/NPC, intact annulus fibrosis/nucleus pulposus tissue; dAFC/NPC, degenerated annulus fibrosis/nucleus pulposus tissue; PGB, pregabalin; CHAD, chondroadherin; COL2A1, type II collagen; HIF-1 $\alpha$, hypoxia-inducible factor-1 $\alpha$.

Kim et al (28) created a facet joint degeneration model via percutaneous puncture-induced injury in rats. Rats were administered with selective cox-2 inhibitors, non-steroidal anti-inflammatory drugs (NSAIDs) and analgesic drugs, including PGB. They underlined that NSAID and PGB applications did not exert any analgesic effect (28). The indications section contained in the pharmacopoeial product mopnography and/or prospectus include many unlighted effect mechanisms of PGB or, more importantly, side effects/adverse events. However, in many branches of medicine, clinicians bravely prescribe this medicine. In the current study, it was, therefore, aimed to investigate the unlighted effects of PGB on intervertebral disc tissues.

Jang et al (29) reported that neuropathic pain developing secondary to peripheral nerve damage causes inflammation in the traumatic region. They aimed to determine the probable effect of a GABA analogue, developed as an antiepileptic drug, on immunomodulation. The tumoricidal effects of natural killer (NK) cells against YAC-1 murine lymphoma cells and phytohemagglutinin-stimulated $\mathrm{T}$ lymphocyte proliferation were assessed in a neuropathic chronic constriction injury mouse model. NK cell activity and splenocyte proliferation were significantly increased in mice with chronic constriction injury compared with control mice. Furthermore, PGB treatment significantly suppressed NK cell activity and splenocyte proliferation in mice with chronic constriction injury (29).

Salat et al (27) investigated the analgesic, antioxidant, metabolic and toxic effects of PGB, which is frequently prescribed to patients with diabetes for the management of neuropathic pain syndrome. They concluded that PGB increased the pain threshold in tactile allodynia and thermal hyperalgesia and stated that PGB is an effective analgesic and antiallodynic drug (27). Furthermore, they did not report any antioxidant or cytotoxic effects of PGB (29).

In the present study, $100 \mu \mathrm{M}$ doses of PGB were used and it was demonstrated that PGB suppresses the proliferation of NPCs/AFCs cultures. The majority of previous trials 
have used tissues obtained from animals (10-12). Human and animal tissues may differ in terms of sensitivity; therefore, the results may be misleading (10-12). Commercial cell lines have been used in some studies in place of animal tissues $(20,30,31)$. However, commercial cell lines contain a single cell type and do not have complex coordination of cells with their microenvironment and ECM (10-12). Test results that have been already complicated become more complicated as a result of the inability of the drug to interact with the microstructures such as the ECM in the cell and its surroundings. Furthermore, cell lines often do not have typical genotypic and phenotypic features of the species from which they are derived as they are genetically modified (10-12,32-34).

In the present study, tissues were harvested from patients with lumber disc hernia who had undergone lumbar microdiscectomy. PGB was applied to NPCs/AFCs primary human cultures to determine whether PGB had any toxic effect on these cells. The effect of PGB on HIF-1 $\alpha$, CHAD and COL2A was also assessed. Although using an in vitro experimental setup may be considered to be a study limitation, this was overcome by using human-derived tissues as opposed to animal tissues or commercial cell lines. A major limitation of the present study, however, is the small sample size.

The results of the present study revealed that CHAD and HIF-1 $\alpha$ expression decreased in a time-dependent manner, regardless of whether tissues were intact or degraded and PGB treatment. It was noteworthy that CHAD and HIF-1 $\alpha$ levels in $\mathrm{dAFC} / \mathrm{NPC}$ tissues increased at $48 \mathrm{~h}$. Healthy cells, even if they were degenerated, proliferated quickly and formed the ECM under sustained appropriate conditions. It is believed that the main cause for this increase may be the in vitro experimental setup. Following the diagnosis of the patients, they took prescribed drugs every day. In the in vitro experiment, PGB was applied to the culture medium once at the beginning. In addition, there are compensatory mechanisms in the liver and gastrointestinal systems that are not found in the in vitro experimental environment. Thus, the toxicity of a drug taken into the body is minimized by the first-pass effect mechanism. It should be noted that the PGB agent was applied in vitro in the current study. It may be more appropriate to pharmaco-molecularly evaluate the data obtained following the application of this drug in the clinical setting and to arrive at a definitive result. PGB was applied continuously, as in the clinical setup, the gene expression would change, and proliferation may stop. In summary, PGB may have a cytotoxic effect on AF/NP tissues and so clinicians should consider the risks before prescribing.

\section{Acknowledgements}

Not applicable.

\section{Funding}

No funding was received.

\section{Availability of data and materials}

The analyzed data sets generated during the present study are available from the corresponding author on reasonable request.

\section{Authors' contributions}

NuK contributed to the study concept, design and preparation of manuscript, as well as the acquisition of subjects and data, analysis and interpretation of data, and evaluation of polymerase chain reaction and ELISA analyses. IY contributed to the preparation of human primary cell culture, inverted light microscopy, performance and evaluation of ELISA analyses, as well as the preparation and storage of PGB. DYS contributed to the analysis and interpretation of the data, preparation of human primary cell culture, and performance and evaluation of polymerase chain reaction analyses. HO contributed to the statistical evaluation of the results and the writing of the manuscript. NeK selected the patients who met the inclusion criteria and contributed to the statistical evaluation of results. $\mathrm{NuK}, \mathrm{NeK}, \mathrm{YEK}, \mathrm{YA}, \mathrm{MSG}$ and KO diagnosed and performed surgery on the patients, and contributed to the removal of tissues from the cases and the transfer of the tissues to the laboratory. OA, HO, NuK, DYS and IY contributed to the preparation and critical revision of the manuscript for important intellectual content. All authors have read and approved the final version of the manuscript.

\section{Ethics approval and consent to participate}

The present study was approved by the ethics committee of the Namik Kemal University School of Medicine (Tekirdag, Turkey; approval no. 2017/41/04/01).

\section{Patient consent for publication}

Written permission was given by all study subjects for publication of their information at the Republic of Turkey, Ministry of Health, Tekirdag State Hospital, Clinics of Neurosurgery. Written informed consent was obtained from all study subjects.

\section{Competing interests}

The authors declare that they have no competing interests.

\section{References}

1. Goodman CW and Brett AS: Gabapentin and pregabalin for pain-is increased prescribing a cause for concern? N Engl J Med 377: 411-414, 2017.

2. Bian F, Li Z, Offord J, Davis MD, McCormick J, Taylor CP and Walker LC: Calcium channel alpha2-delta type 1 subunit is the major binding protein for pregabalin in neocortex, hippocampus, amygdala, and spinal cord: An ex vivo autoradiographic study in alpha2-delta type 1 genetically modified mice. Brain Res 1075: 68-80, 2006.

3. Blommel ML and Blommel AL: Pregabalin: An antiepileptic agent useful for neuropathic pain. Am J Health Syst Pharm 64: 1475-1482, 2007.

4. Zarei M, Najafi A, Mansouri P, Sadeghi-Yazdankhah S, Saberi H, Moradi $M$ and Farzan M: Management of postoperative pain after lumbar surgery-pregabalin for one day and 14 days-a randomized, triple-blinded, placebo-controlled study. Clin Neurol Neurosurg 151: 37-42, 2016.

5. Roth T, Arnold LM, Garcia-Borreguero D, Resnick M and Clair AG: A review of the effects of pregabalin on sleep disturbance across multiple clinical conditions. Sleep Med Rev 18: 261-271, 2014.

6. Foroutan $\mathrm{N}$ and Nikvarz $\mathrm{N}$ : Role of pregabalin in management of pruritus: A literature review. J Pharm Pharm Sci 19: 465-474, 2016. 
7. Gazulla J, Ruiz-Gazulla C and Tintore M: GABAergic pharmacotherapy in the treatment of motor disorders of the central nervous system. Curr Pharm Des 21: 4989-4995, 2015.

8. Akyuva Y, Karaarslan N, Yilmaz I, Ozbek H, Sirin DY, Gurbuz MS, Kaya YE, Kaplan N and Ates O: How scaffolds, which are polymeric drug delivery systems allowing controlled release, can be tested in human primary nucleus pulposus and annulus fibrosus cell cultures? Merit Res J Med Med Sci 5 : 477-487, 2017

9. Karaarslan N, Yilmaz I, Ozbek H, Sirin Yasar D, Kaplan N, Akyuva Y, Gonultas A and Ates O: Are specific gene expressions of extracellular matrix and nucleus pulposus affected by primary cell cultures prepared from intact or degenerative intervertebral disc tissue? Turk Neurosurg: Jan 22, 2018 (Epub ahead of print).

10. Komur B, Akyuva Y, Karaslan N, Isyar M, Gumustas SA Yilmaz I, Akkaya S, Sirin DY, Mutlu CA, Batmaz AG, et al: Can a biodegradable implanted bilayered drug delivery system loaded with BMP-2/BMP-12 take an effective role in the biological repair process of bone-tendon injuries? A preliminary report J Pharm (Cairo) 2017: 7457865, 2017.

11. Oznam K, Sirin DY, Yilmaz I, Kaya YE, Isyar M, Gumustas SA, Ozbek H, Akkaya S, Kayhan A and Mahirogullari M: Iopromide- and gadopentetic acid-derived preparates used in MR arthrography may be harmful to chondrocytes. J Orthop Surg Res 12: 98, 2017.

12. Gumustas F, Yilmaz I, Sirin DY, Gumustas SA, Batmaz AG, Isyar M, Akkaya S and Mahirogullari M: Chondrocyte proliferation, viability and differentiation is declined following administration of methylphenidate utilized for the treatment of attention-deficit/hyperactivity disorder. Hum Exp Toxicol 36: 981-992, 2017.

13. Rosenzweig DH, Tremblay Gravel J, Bisson D, Ouellet JA, Weber $\mathrm{MH}$ and Haglund L: Comparative analysis in continuous expansion of bovine and human primary nucleus pulposuscells for tissue repair applications. Eur Cell Mater 33 240-251, 2017.

14. Ehlicke F, Freimark D, Heil B, Dorresteijn A and Czermak P: Intervertebral disc regeneration: Influence of growth factors on differentiation of human mesenchymal stem cells (hMSC). Int J Artif Organs 33: 244-252, 2010.

15. Zhou X, Tao Y, Liang C, Zhang Y, Li H and Chen Q: BMP3 alone and together with TGF- $\beta$ promote the differentiation of human mesenchymal stem cells into a nucleus pulposus-like phenotype. Int J Mol Sci 16: 20344-20359, 2015.

16. Feng G, Jin X, Hu J, Ma H, Gupte MJ, Liu H and Ma PX: Effects of hypoxias and scaffold architecture on rabbit mesenchymal stem cell differentiation towards a nucleus pulposus-like phenotype. Biomaterials 32: 8182-8189, 2011.

17. Li XC, Wu YH, Bai XD, Ji W, Guo ZM, Wang CF, He Q and Ruan DK: BMP7-Based functionalized self-assembling peptides protect nucleus pulposus-derived stem cells from apoptosis 1n vitro. Tissue Eng Part A 22: 1218-1228, 2016.

18. Emanuel KS, Vergroesen PP, Peeters M, Holewijn RM, Kingma I and Smit TH: Poroelastic behaviour of the degenerating human intervertebral disc: A ten-day study in a loaded disc culture system. Eur Cell Mater 29: 330-340, 2015.

19. Risbud MV and Shapiro IM: Notochordal cells in the adult intervertebral disc: New perspective on an old question. Crit Rev Eukaryot Gene Expr 21: 29-41, 2011.

20. Van den Akker GG, Surtel DA, Cremers A, Rodrigues-Pinto R, Richardson SM, Hoyland JA, van Rhijn LW, Welting TJ and Voncken JW: Novel immortal human cell lines reveal subpopulations in the nucleus pulposus. Arthritis Res Ther 16: R135, 2014
21. Imabuchi R, Ohmiya Y, Kwon HJ, Onodera S, Kitamura N, Kurokawa T, Gong JP and Yasuda K: Gene expression profile of the cartilage tissue spontaneously regenerated in vivo by using a novel double-network gel: Comparisons with the normal articular cartilage. BMC Musculoskelet Disord 12: 213, 2011

22. Zeng Y, Danielson KG, Albert TJ, Shapiro IM and Risbud MV HIF-1 alpha is a regulator of galectin-3 expression in the intervertebral disc. J Bone Miner Res 22: 1851-1861, 2007.

23. Risbud MV, Schipani E and Shapiro IM: Hypoxic regulation of nucleus pulposus cell survival: From niche to notch. Am J Pathol 176: 1577-1583, 2010.

24. Hanley EN Jr and McCulloch JA: Surgical indication and techniques international society for the study of the lumbar spine: The lumbar spinethe lumbar spine 2nd edition. WB Saunders, Philadelphia, PA, pp492-524, 1996.

25. Livak KJ and Schmittgen TD: Analysis of relative gene expression data using real-time quantitative PCR and the 2(-Delta Delta C(T)) method. Methods 25: 402-408, 2001.

26. Taylor CP, Angelotti T and Fauman E: Pharmacology And mechanism of action of pregabalin: The calcium channel alpha2-delta (alpha2-delta) subunit as a target for antiepileptic drug discovery. Epilepsy Res 73: 137-150, 2007.

27. Salat K, Librowski T, Nawiesniak B and Gluch-Lutwin M: Evaluation of analgesic, antioxidant, cytotoxic and metabolic effects of pregabalin for the use in neuropathic pain. Neurol Res 35: 948-958, 2013.

28. Kim JS, Ahmadinia K, Li X, Hamilton JL, Andrews S, Haralampus CA, Xiao G, Sohn HM, You JW, Seo YS, et al: Development of an experimental animal model for lower back pain by percutaneous injury-induced lumbar facet joint osteoarthritis. J Cell Physiol 230: 2837-2847, 2015.

29. Jang Y, Song HK, Yeom MY and Jeong DC: The immunomodulatory effect of pregabalin on spleen cells in neuropathic mice. Anesth Analg 115: 830-836, 2012.

30. Growney Kalaf EA, Flores R, Bledsoe JG and Sell SA: Characterization of slow-gelling alginate hydrogels for intervertebral disc tissue-engineering applications. Mater Sci Eng C Mater Biol Appl 63: 198-210, 2016.

31. Liu MC, Chen WH, Wu LC, Hsu WC, Lo WC, Yeh SD, Wang MF, Zeng R and Deng WP: Establishment of a promising human nucleus pulposus cell line for intervertebral disc tissue engineering. Tissue Eng Part C Methods 20: 1-10, 2014.

32. Gumustas SA, Yilmaz I, Isyar M, Sirin DY, Batmaz AG, Ugras AA, Oznam K, Ciftci Zand Mahirogullari M: Assessing the negative impact of phenyl alkanoic acid derivative, a frequently prescribed drug for the suppression of pain and inflammation, on the differentiation and proliferation of chondrocytes. J Orthop Surg Res 11: 70, 2016.

33. Isyar M, Yilmaz I, Yasar Sirin D, Yalcin S, Guler O and Mahirogullari M: A practical way to prepare primer human chondrocyte culture. J Orthop 13: 162-167, 2016.

34. Guzelant AY, Isyar M, Yilmaz I, Sirin DY, Cakmak S and Mahirogullari M: Are chondrocytes damaged when rheumatologic inflammation is suppressed? Drug Chem Toxicol 40: 13-23, 2017.

This work is licensed under a Creative Commons Attribution-NonCommercial-NoDerivatives 4.0 International (CC BY-NC-ND 4.0) License. 